\title{
Starostne razlike in razlike med spoloma v agresivnosti slovenskih učencev in dijakov
}

\author{
Ana Kozina* \\ Pedagoški inštitut
}

\begin{abstract}
Povzetek: V raziskavi smo preučevali razlike v agresivnosti med spoloma in med različnimi starostnimi skupinami na vzorcih slovenskih učencev in dijakov. Zajeti so bili trije reprezentativni vzorci: mlajši učenci (učenci 4. razreda osnovne šole), starejši učenci (učenci 8. razreda osnovne šole) ter dijaki (dijaki 4. letnikov programov splošne mature). Analize so temeljile na rezultatih lestvice agresivnosti LA, ki meri splošno agresivnost in štiri specifične vrste agresivnosti: telesna agresivnost (TA), besedna agresivnost (BA), notranja agresivnost (NA) in agresivnost v odnosu do avtoritete (AA). Z dvosmerno analizo variance smo ugotovili pomemben učinek spremenljivk spola, starosti ter pomembne učinke interakcije obeh spremenljivk (spol in starost) na agresivnost učencev in dijakov. Ugotovili smo pomembne razlike med spoloma v skupini starejših učencev in v skupini mlajših učencev, ne pa tudi dijakov. Učenci, tako starejši kot mlajši, so bili bolj agresivni v primerjavi z učenkami. Starejši učenci so bili v primerjavi z mlajšimi učenci bolj besedno agresivni, bolj telesno agresivni, bolj notranje agresivni in bolj agresivni v odnosu do avtoritete. Dijaki so bili v primerjavi z obema skupinama učencev manj telesno agresivni, manj besedno agresivni, bolj notranje agresivni, v agresivnosti v odnosu do avtoritete pa so se nahajali med obema skupinama učencev. Vzorec razlik med različnimi skupinami je skladen z izsledki strokovne literature, ki ugotavljajo višjo agresivnost pri moškem spolu in različne razvojne poti za različne vrste agresivnosti, kar so potrdili tudi naši podatki. Raziskava je podala pomembne primerjave agresivnosti na slovenskih vzorcih in obenem odprla nova raziskovalna vprašanja, vezana predvsem na merjenje in preverjanje bolj posrednih oblik agresivnosti, ki so značilnejše za ženski spol in dijake.
\end{abstract}

Ključne besede: agresivnost, učenci, dijaki, razlike med spoloma, starostne razlike

\section{Age and gender differences in aggression of Slovene elementary and secondary school students}

\author{
Ana Kozina \\ Educational Research Institute, Slovenia
}

\begin{abstract}
The study examined age and gender differences in aggression using three representative samples for Slovenia: $4^{\text {th }}$ grade elementary school students; $8^{\text {th }}$ grade elementary school students; $4^{\text {th }}$ grade secondary school students in Matura programs. The results were based on the LA aggression scale that measures general aggression and four specific types of aggression: physical aggression (TA), verbal aggression (BA), internal aggression (NA) and aggression towards authority (AA). Based on the results of two-way ANOVA we found important effects of age, gender and their interaction. The gender differences were significant in the groups of elementary school students but not in secondary school students. Male elementary school students, $4^{\text {th }}$ and $8^{\text {th }}$ grade, were more aggressive compared to female elementary school students. $8^{\text {th }}$ grade elementary school students were more physically, verbally, internally aggressive and more aggressive towards authority when compared to $4^{\text {th }}$ grade elementary school students. Secondary school students were significantly less physically and verbally aggressive, and on the other hand more internally aggressive when compared to both groups of elementary school students. Secondary school students reported higher level of aggression towards authority than $4^{\text {th }}$ grade elementary students, and lower level then $8^{\text {th }}$ grade elementary students. The results were congruent with the findings of the research literature indicating higher aggression of males when compared to females and different developmental paths for different types of aggression in question. The study introduced important findings regarding age and gender differences in representative school samples in Slovenia and proposed future research mostly in direction of including measures of indirect aggression that is linked to female gender and older students.
\end{abstract}

Key words: aggression, elementary school students, secondary school students, gender differences, age differences

${ }^{*}$ Naslov/Address: dr. Ana Kozina, Pedagoški inštitut, Gerbičeva 62, 1000 Ljubljana; e-pošta: ana.kozina@pei.si

Članek je licenciran pod pogoji Creative Commons Attribution 4.0 licence. / The article is licensed under a Creative Commons Attribution 4.0 International License. 
Agresivno vedenje opredelimo kot vedenje, $\mathrm{s}$ katerim oseba namerava povzročiti oz. dejansko povzroči telesno ali psihološko škodo sebi ali drugemu (Krug, Dahlberg, Mercy, Zwi in Lozano, 2002; Lamovec, 1988). Agresivnost se lahko kaže na različne načine. Opredelitev različnih vrst agresivnosti je pomembna zaradi lažjega razumevanja vzrokov agresivnosti, z njo povezanih dejavnikov in načinov njenega preprečevanja ter zmanjševanja (Flannery, Vazsonyi in Waldman, 2007). Najširše lahko agresivnost razdelimo na kolektivno agresivnost in individualno agresivnost. Individualno agresivnost delimo na agresivnost, usmerjeno nase, in agresivnost, usmerjeno na druge (WHO, 1996, citirano v: Flannery idr., 2007). Individualno agresivnost, usmerjeno nase in na druge, lahko dalje razvrščamo po usmeritvi na notranje in zunanje oblike ter po funkciji na reaktivno in proaktivno agresivnost. $\mathrm{V}$ prispevku smo analizirali razlike v posameznih vrstah agresivnosti med spoloma in po starosti in na ta način preverili, ali so razlike med spoloma konsistentne ne glede na vrsto agresivnosti ter kako se vključene starostne skupine razlikujejo glede na vrste agresivnosti.

\section{Agresivnost in spol}

Velikost razlik $\mathrm{v}$ agresivnosti med spoloma je odvisna od oblike agresivnosti, ki jo merimo, zato smo tudi $\mathrm{v}$ prispevku razlike med spoloma analizirali po posameznih oblikah agresivnosti. Večina raziskav, ki se ukvarjajo $\mathrm{z}$ agresivnostjo, kaže pomembne razlike med spoloma (Condon, Morales-Vives, Ferrando in Vigil-Colet, 2006; Connor, 2002; Delfos, 2004; Finn in Frone, 2003; Huesmann, 1994; Renfrew, 1997). $\mathrm{V}$ večini moški spol kaže višje stopnje agresivnosti v primerjavi z ženskim (Archer, 1991; Campbell in Henry, 1999; Condon idr., 2006; Finn in Frone, 2003). $\mathrm{V}$ največjem delu se raziskave razlik $\mathrm{v}$ agresivnosti med spoloma osredototočajo na telesno agresivnost (Buss in Perry, 1992; Condon idr., 2006). Te enoznačno poročajo o višji telesni agresivnosti moškega spola. Vendarle pa raziskave (Huesmann, 1994) kažejo tudi, da razlike niso omejene le na telesno agresivnost, temveč moški spol $\mathrm{v}$ primerjavi z ženskim izkazuje tudi več besedne in posredne agresivnosti. So pa razlike med spoloma večje $\mathrm{v}$ telesni agresivnosti (Huesmann, 1994; Marjanovič Umek in Zupančič, 2004). Razmerje med spoloma je skladno tudi $z$ večjim številom fantov $\mathrm{z}$ opozicionalno motnjo, katere jedro je agresivnost, v primerjavi z dekleti (Kocmur, 1999). Razlike med spoloma so prisotne že zgodaj v otroštvu, že pri starosti dveh let in pol, in se z razvojem ohranjajo (Nagin in Tremblay, 2001). Drugi avtorji (Archer in Coyne, 2005; Connor, 2002; Lagerspetz, Bjorqvist in Peltonen, 1988) so ugotovili nasprotno, da so razlike med spoloma večje $\mathrm{v}$ otroštvu in do odraslosti izzvenijo.
Več fantov $\mathrm{v}$ primerjavi $\mathrm{z}$ dekleti je reaktivno agresivnih, medtem ko pri proaktivni agresivnosti razlike med spoloma niso pomembne (Brendgen, Vitaro, Boivin, Dionne in Perusse, 2006). Za reaktivno agresivnost so za razliko od proaktivne značilni kaznovalni vzorci vzgoje (Brendgen, idr. 2006), zaznavanje namenov drugih kot sovražnih (Connor, 2002; Wilkowski in Robinson, 2010), slabši šolski uspeh, slabša samopodoba, depresivnost (Vitaro, Brendgen in Barker, 2006), anksioznost, težave $\mathrm{v}$ kognitivnem in socialno kognitivnem delovanju (Connor, 2002; Poulin in Boivin, 2000; Vitaro idr., 2006), nesprejetost (Connor, 2002; Hubbert, McAuliffe, Morrow in Romano, 2010; Vitaro idr., 2006) in dovzetnost za agresivna vedenja drugih (Connor, 2002). Reaktivna agresivnost ima čustveno podlago (Fite, Raine, Stouthamer-Loeber, Loeber in Pardini, 2010; Hubbert idr., 2010) in je najpogosteje odgovor na realno ali nerealno zaznano provokacijo, frustracijo ali grožnjo (Connor, 2002; Hubbert idr., 2010; Vitaro idr., 2006). Čustvena podlaga reaktivne agresivnosti je jeza (Wilkowski in Robinson, 2010). Lagerspetz in sodelavci (1988) ugotavljajo, da moški več poročajo o jezi, je pa trajanje jeze daljše pri ženskah.

Neposredna agresivnost je bolj značilna za moški kot za ženski spol. Neposredne oblike agresivnosti imajo jasen namen škodovati sebi ali drugemu. Najbolj pogosti vrsti neposredne agresivnosti sta telesna in besedna agresivnost. Telesna agresivnost zajema udarce, brce, ugrize, uporabo orožja in pretepe, lahko tudi grožnje telesne agresivnosti. Besedna agresivnost zajema povzročanje škode drugemu $\mathrm{z}$ besedami, kričanjem in žaljivkami (Flannery idr., 2007). Posredna agresivnost povzroča psihološko, $\mathrm{v}$ redkih primerih tudi telesno škodo drugemu, s sredstvi socialne manipulacije, tako da ostane namen škodovati drugemu prikrit. Posredne oblike agresivnosti so lahko besedne (npr. govorice) in telesne (npr. poškodovanje lastnine drugega). Raziskave kažejo, da ima posredna agresivnost podobne negativne posledice kot neposredna in je podobno s strani drugih zaznana kot jezno sovražno dejanje (Connor, 2002; Crick, Ostrov in Werner, 2006). Posredna agresivnost je odvisna od stopnje razvoja posameznika ter od kvalitete njegove socialne mreže in se $\mathrm{v}$ razvoju pojavi kasneje kot neposredna agresivnost. Posredna agresivnost se $\mathrm{v}$ večji meri povezuje z ženskim kot moškim spolom (Archer in Coyne, 2005).

Empirično ugotovljene razlike med spoloma lahko med drugim pripišemo različnim načinom izražanja agresivnosti pri moških in ženskah, kulturnim stereotipom in metodi merjenja agresivnosti. Kot omenjeno zgoraj, moški izražajo bolj neposredne oblike agresivnosti in ženske bolj posredne oblike agresivnosti (Archer, 1991; Archer in Coyne, 2005; Condon idr., 2006; Connor, 2002; Crick idr., 2006; Hudley, 1993; Lagerspetz idr.,1988; Marjanovič Umek 
in Zupančič, 2004). Posameznik uporabi posredno agresivnost, ko je neposredna nedostopna. Za ženski spol je agresivno vedenje manj sprejemljivo in zato uporabljajo bolj posredne oblike. Raziskave $\mathrm{v}$ nadzorovanih pogojih kažejo, da se ženske enako kot moški odzivajo agresivno, ko se čutijo izzvane ter ko ocenijo, da je agresivno vedenje $\mathrm{v}$ dani situaciji primerno in pričakovano (Connor, 2002; Huesmann, 1994). Se pa ženske odzivajo manj agresivno, kadar ni zunanjega povoda za agresivno vedenje (Huesmann, 1994). Druge razlage govorijo o tem, da posameznik škodi drugemu na področju, ki ga sam ocenjuje kot pomembnega. Tako na primer moški višje vrednotijo telesno moč in dominantnost, medtem ko ženske višje vrednotijo odnose med posamezniki in družbeni položaj (Connor, 2002). S tem se povezuje tudi višja socialna inteligentnost žensk in bolj na čustva vezani odnosi, ki dopuščajo več možnosti za posredno agresivnost (Archer in Coyne, 2005; Huesmann, 1994). Flannery kot enega izmed oteževalnih dejavnikov za uporabo posredne agresivnosti pri moškem spolu postavlja počasnejši razvoj besednih spretnosti, zaradi katerih naj bi bila njihova zgodnja socializacija otežena in agresivno vedenje bolj pogosto (Flannery idr., 2007).

Razlike med spoloma lahko pripišemo tudi metodi merjenja in okolju, v katerem opazujemo agresivnost. Pri merjenju agresivnosti pogosto uporabljamo ocene vrstnikov, učiteljev in staršev, ki bolj opazijo neposredne oblike agresivnosti, bolj značilne za moški spol, in manj posredne oblike, značilne za ženski spol. Razlike med spoloma so manjše, ko uporabljamo samoocenjevalne tehnike, laboratorijske pogoje in eksperimentalno situacijo.

Ob upoštevanju različnih načinov izražanja agresivnosti, situacijske odvisnosti ter vpliva kulture in socializacije so vzroki in dispozicije za agresivnost za oba spola enaki (Flannery idr., 2007; Huesmann, 1994). Razlike pripisujemo predvsem različnim načinom izražanja agresivnosti pri ženskah oziroma moških. Ne glede na to, ali razlike obstajajo tudi na ravni vzrokov, dispozicij in tako imenovane splošne agresivnosti, pa moramo na ravni posameznih vrst agresivnosti upoštevati razlike med spoloma, ko načrtujemo obravnavo. Kot smo opredelili zgoraj, so nekatere vrste agresivnosti bolj značilne za moški spol in druge za ženski. Posledice agresivnosti pa so bolj negativne, ko oblika agresivnosti ni skladna z spolom. Na primer bolj negativne so posledice za ženske, ki so neposredno agresivne, in za moške, ki so posredno agresivni. Tovrsten odnos so ugotovili Crick in sodelavci (2006) v primerjavah posledic neposredne (telesne) in posredne (odnosne) agresivnosti na težave internalizacije in težave eksternalizacije. Spremljali so učence v prvem razredu osnovne šole do njihovega četrtega razreda. Ugotavljali so, kako se kažejo posledice agresivnosti v skupini, ki je bila posredno agresivna, v skupini, ki je bila neposredno agresivna in $\mathrm{v}$ skupini, ki je bila tako posredno kot neposredno agresivna. Ugotovili so, da so največje število negativnih posledic v skupini, ki je tako posredno kot neposredno agresivna ter da so posledice bolj negativne, če oblika agresivnosti ni skladna $\mathrm{s}$ spolom (na primer pri dekletih, ki so neposredno agresivne ali pri fantih, ki so posredno agresivni).

\section{Agresivnost in starost}

Raziskave kažejo različne spremembe v agresivnem vedenju tekom razvoja posameznika. Nekatere kažejo starostni upad (Cairns, Cairns, Neckerman, Ferguson in Gariepy, 1989; Hyde, 1984; Park in Slaby, 1983, oboje citirano v: Hudley, 1993), druge porast (Whiting in Whiting, 1975, citirano v: Hudley, 1993) in tretje, da so posamezniki $v$ srednjem in poznem otroštvu bolj agresivni od mlajših in starejših posameznikov (Huesmann, 1994). Strokovnjaki večinoma menijo, da je porast ali upad agresivnosti odvisen od vrste agresivnosti, ki jo opazujemo (Huesmann, 1994). Raziskovalci se strinjajo, da telesna agresivnost upada, in pri tem podajajo tudi natančnejše, čeprav ne enotne, časovne okvire: telesna agresivnost doseže svoj vrhunec v starosti dveh do štirih let in kasneje upade (Connor, 2002); upada od 8. do 18. leta (Cairns idr., 1989; Vitaro idr., 2006); upada od 4. do 11. leta (Tremblay, 2000). Za besedno agresivnost nekateri avtorji ugotavljajo, da narašča od 8. do 11. leta in potem rahlo upade do 18 . leta (Romano, Tremblay, Boulerice in Swisher, 2005), drugi pa trdijo, da doseže svoj vrhunec v starosti dveh do štirih let in kasneje upade (Connor, 2002). Posredna agresivnost narašča od 8. do 11. leta in potem rahlo upade do 18. leta (Romano idr., 2005).

Model razvoja agresivnosti Bjorkquista in sodelavcev (citirano v: Vitaro idr., 2006) vključuje tako neposredne kot tudi posredne oblike agresivnosti. Glede na njihov model otroci v najzgodnejšem obdobju uporabljajo telesno agresivnost zato, ker še ne zmorejo izražati agresivnosti na druge načine. Do podobnih zaključkov so prišli tudi klinični raziskovalci, ki so ugotavili, da se otroci in mladostniki, ki imajo nižje besedno kognitivne sposobnosti ali drugačne težave pri govoru, ki onemogočajo ubeseditev konflikta, pogosteje kot ostali odzivajo s telesno agresivnostjo (Connor, Steingard, Cunningham, Andreson in Melloni, 2004). Z razvojem besednih in socialnih spretnosti otroci pričnejo sprva $\mathrm{z}$ uporabo besedne agresivnosti in kasneje $z$ vedno večjim nadzorom lastnih čustev in usvajanjem pravil o sprejemljivem vedenju dodajo še posredno agresivnost (Vitaro idr., 2006). Da se v obdobju srednjega in poznega otroštva agresivnost najpogosteje pojavlja $\mathrm{V}$ povezavi $\mathrm{z}$ medosebnimi odnosi, sta ugotavili tudi L. Marjanovič Umek in M. Zupančič (2004) in dodajata, da so v tem obdobju pogostejše tudi druge oblike agresivnega vedenja, kot 
so laganje, goljufanje in kraja, ki imajo tudi posredni značaj. Govorimo lahko o premiku od neposrednih $\mathrm{k}$ posrednim oblikam agresivnosti. O tem premiku poročajo tudi novejše raziskave agresivnosti dvojčkov, ki so ugotovile, da povečana telesna agresivnost vodi $\mathrm{v}$ povečano posredno agresivnost, medtem ko obratno ne drži (Vitaro idr., 2006).

Analogno lahko govorimo o premiku od reaktivne k proaktivni agresivnosti (Archer in Coyne, 2005; Huesmann, 1994; Krall, 2003; Tremblay, 2000). Reaktivna je bolj značilna za zgodnje obdobje in proaktivna za poznejše, ko so otroci in mladostniki spretnejši pri načrtovanju in so tudi kognitivne sposobnosti ustrezno razvite (Connor idr., 2004).

Ugotovitev o različnih oblikah agresivnosti $\mathrm{v}$ različnih razvojnih obdobjih je skladna tudi $\mathrm{Z}$ raziskavami, ki kažejo, da je agresivnost stabilna lastnost (Connor, 2002; Hudley, 1993; Huesmann, Eron, Lefkowitz in Walder, 1984; Loeber in Hay, 1997; Olweus, 1979; Overton, 2004). Nekateri raziskovalci celo menijo, da je njena stabilnost primerljiva $\mathrm{s}$ stabilnostjo intelektualnih sposobnosti (Carr, 1998; Ferris, 1996; Fossati, Maffei, Acquarini in Ceglie, 2003; Van Lier in Crijhen, 2005). Olweus (1979) je $\mathrm{v}$ pregledu 16 vzdolžnih raziskav o stabilnosti agresivnosti poročal o koeficientih stabilnosti od 0,79 do $0,81 \mathrm{v}$ časovnih intervalih od 6 mesecev do 21 let (povprečni časovni interval 5,7 let, povprečna velikost vzorca je 116). Da ugotovimo stabilnost agresivnosti $\mathrm{v}$ času, moramo spremljati iste posameznike $\mathrm{v}$ tistih razvojnih obdobjih, ki so predmet našega zanimanja. Raziskav, ki bi bile zastavljene tako dolgoročno, je malo (npr. Dunedin Study, California Youth Authority Study, The South Holland Epidemiological Study, The Oregon Youth Study; pregled v: Huesmann, 1994), vse pa kažejo, da agresivnost $\mathrm{v}$ otroštvu vodi $\mathrm{v}$ agresivnost v mladostništvu in odrasli dobi ali v druge oblike prilagoditvenih težav (Flannery idr., 2007; Huesmann idr., 1984; Olweus, 1979). Ker agresivnost s starostnimi obdobji spreminja obliko, njeno stabilnost v času Kagan in Moss (1962, citirano v: Huesmann, 1994) opredeljujeta kot heterotipsko. Za heterotipsko stabilnost je značilno, da je neka značilnost tekom razvoja stabilna, se pa skozi različna razvojna obdobja različno kaže (Huesmann, 1994). Zanimivo je, da se stabilnost agresivnosti razlikuje glede na spol. Nekatere raziskave so sicer pokazale podobno stopnjo stabilnosti, na primer Cairns in sodelavci (1989) so našli koeficiente stabilnosti za moški spol 0,49 in za ženski spol 0,51, druge raziskave pa so pokazale nižjo stabilnost pri ženskem spolu (npr. Kagan in Moss, 1962; Mcgee, Feehan, Williams in Andreson, 1994; Olweus, 1979, vse citirano v: Connor, 2002). Eron (1992, citirano v: Connor, 2002) je v obdobju od starosti 8 do 30 let ugotovil koeficient stabilnosti 0,50 za moški spol in 0,34 za ženski spol. $\mathrm{Ob}$ tem se časovna stabilnost agresivnosti pri ženskah kaže bolj heterotipsko kot časovna stabilnost agresivnosti pri moških. To pomeni, da se agresivnost pri ženskah kaže skozi različne težave $\mathrm{v}$ splošnem delovanju $\mathrm{v}$ odrasli dobi (Connor, 2002). Ne smemo pa zanemariti, da je stabilnost odvisna tudi od izbora metode merjenja in da lestvice agresivnosti večinoma merijo bolj tipično moške oblike agresivnosti (Connor, 2002; Huesmann, 1994). Stabilnost je na primer pri moških večja, in s tem razlike v stabilnosti agresivnosti med spoloma manjše, kadar jo merimo s pomočjo pogostosti kriminalnih vedenj v odrasli dobi in če jo merimo skozi daljše časovno obdobje (Connor, 2002).

V prispevku smo preučili vzorec razlik v agresivnosti med spoloma na treh velikih reprezentativnih vzorcih učencev in dijakov v Sloveniji. S primerjavo agresivnosti med vzorci smo preverili, kako se agresivnost razlikuje med različnimi starostnimi skupinami. Glede na rezultate drugih raziskav smo pričakovali višje ravni agresivnosti pri moškem spolu. Pričakovali smo tudi višje ravni telesne in besedne agresivnosti pri mlajših udeležencih v primerjavi s starejšimi. Pričakovali smo višje ravni notranje agresivnosti pristarejšihudeležencih $\mathrm{v}$ primerjavi z mlajšimi udeleženci. $\mathrm{V}$ prispevku smo se osredotočili predvsem na učinek interakcije spola in starosti na agresivnost, torej preverili smo, ali so razlike med spoloma različne $\mathrm{v}$ različnih starostnih skupinah in ali se razlike $\mathrm{v}$ agresivnosti med različnimi starostnimi skupinami razlikujejo glede na to, ali agresivnost merimo pri dekletih ali pri fantih. Raziskava, ki bi spol in agresivnost obravnavala na tako velikih in reprezentativnih vzorcih v Sloveniji še ni bila izvedena. $\mathrm{Z}$ analizo razlik navelikih reprezentativnih vzorcih je prispevek hkrati s preverjenjem stabilnosti predhodno ugotovljenih razlik v agresivnosti med spoloma tudi ponudil trdnejšo osnovo za obravnavo agresivnosti $\mathrm{v}$ šolah glede na to ali so v obravnavi dekleta ali fantje. $\mathrm{Na}$ ta način prispevek omogoča širšo analizo agresivnosti (vključuje analizo interakcije spola in starosti za štiri merjene oblike agresivnosti), ki ima praktično vrednost predvsem za obravnavo agresivnosti $v$ šolah.

\section{Metoda}

\section{Udeleženci}

$\mathrm{V}$ analize je bil zaradi visoke reprezentativnosti vključen vzorec učencev in dijakov, ki so sodelovali v mednarodnih raziskavah trendov znanja matematike in naravoslovja TIMSS 2007 in TIMSS za maturante 2008. Vzorec učencev iz raziskave TIMSS 2007 je predstavljal reprezentativen vzorec učencev četrtih (mlajši učenci) in osmih razredov (starejši učenci) osnovne šole. Vzorec mlajših učencev je sestavljalo 5284 učencev četrtega razreda, od teh 2621 učencev in 2663 učenk 
(12 manjkajočih podatkov). Njihova povprečna starost je bila 9,8 let. Vzorec starejših učencev je vključeval 5143 učencev osmega razreda, od tega 2545 učencev in 2569 učenk (29 manjkajočih podatkov). Povprečna starost osmošolcev je bila 13,8 let. Vzorčenje je bilo stratificirano, pri čemer so bili kot stratumi določene geografske regije Slovenije, znotraj teh pa je potekalo naključno izbiranje šol. Naključno je bilo tako izbranih 150 osnovnih šol. Znotraj izbranih šol so bili ponovno naključno izbrani posamezni oddelki med četrtimi in osmimi razredi, po eden ali dva na vsako šolo. Naključno vzorčenje je potekalo s programom WinW3S (IEA DPC, verzija 2006), ki je bil posebej za ta namen razvit $v$ mednarodnih centrih raziskave TIMSS. Izbrani razredi na šoli so bili v raziskavo vključeni v celoti, v kolikor je bilo pridobljeno soglasje staršev (Japelj Pavešič, Svetlik, Rožman in Kozina, 2008).

Način vzorčenja dijakov za raziskavo TIMSS 2008 za maturante je bil nekoliko drugačen. Posebnost vzorčenjaje bila, da so bile zaradi zahteve po mednarodni primerljivosti vzorca $v$ raziskavo vključene vse srednje šole s programom splošne mature v Sloveniji in znotraj njih vsi dijaki, ki so se pripravljali na maturo iz fizike ter vzorec dijakov, ki so se pripravljali na maturo iz matematike. Vzorec dijakov je tako sestavljalo 3343 dijakov, od teh 1743 fantov in 1600 deklet (12 manjkajočih podatkov). Njihova povprečna starost je bila 18,8 let (Japelj Pavešić, Svetlik, Kozina in Rožman, 2009).

\section{Pripomočki}

LA lestvica agresivnosti (Kozina, 2012) vsebuje 18 postavk in je oblikovana za merjenje splošne ravni agresivnosti (reaktivne agresivnosti) ter posameznih faktorjev agresivnosti učencev in dijakov $\mathrm{v}$ šolskem okolju: telesna agresivnost (TA); besedna agresivnost (BA), notranja agresivnost (NA) in agresivnost $\mathrm{V}$ odnosu do avtoritete (AA). Štiri-faktorska hierarhična struktura lestvice je bila potrjena s konfirmatorno faktorsko analizo $\mathrm{z}$ istimi vzorci učencev (RMSEA = 0,067; CFI $=0,912$; TLI $=0,897$; $\mathrm{SRMR}=0,047)$ in dijakov $(\mathrm{RMSEA}=0,076$; $\mathrm{CFI}=0,895$; $\mathrm{TLI}=0,876$; SRMR $=0,049)$. Faktor TA zajema 6 postavk, ki se vsebinsko nanašajo na izražanje agresivnosti $\mathrm{s}$ pomočjo telesa, s tepeži, udarci, potiskanjem... (npr. Velikokrat udarim koga drugega; V šoli se pogostokrat pretepam). Faktor BA zajema 4 postavke, ki merijo izražanje agresivnosti $\mathrm{z}$ besedami, na primer $\mathrm{S}$ kričanjem, opravljanjem, prerekanjem... (npr. Če me kdo užali, ga užalim nazaj; Ko se s kom prepiram, sem zelo glasen/glasna). Faktor $N A$ zajema 4 postavke in meri agresivnost umerjena navznoter v obliki slabega počutja, občutkov krivde (npr. Pogosto se mi zdi, da se mi dogajajo same slabe stvari; Na splošno mi gre veliko ljudi na živce). Faktor AA zajema 4 postavke in meri usmerjenost agresivnosti proti avtoriteti učiteljev in staršev (npr.: Če se ne strinjam s pravili učiteljev, jih prekršim; Rad nalašč izzivam starše). Lestvica meri agresivnost na 5-stopenjski lestvici $(1=$ nikoli, $2=$ redko, $3=$ včasih, $4=$ pogosto, $5=$ vedno). Vse postavke so pozitivno vrednotene. Večja vrednost pomeni višjo stopnjo agresivnosti. Lestvice so se izkazale kot zadovoljivo zanesljive (uporabljen je Cronbachov $\alpha$ kot mera notranje skladnosti) tako pri učencih $\left(\alpha_{T A}=0,84\right.$; $\left.\alpha_{B A}=0,74 ; \alpha_{N A}=0,72 ; \alpha_{A A}=0,78\right)$ kot pri dijakih $\left(\alpha_{T A}=\right.$ 0,$\left.80 ; \alpha_{B A}=0,70 ; \alpha_{N A}=0,72 ; \alpha_{A A}=0,70\right)$.

\section{Postopek}

$\mathrm{V}$ raziskavo vključeni učenci in dijaki so lestvico LA izpolnjevali na dan izvedbe mednarodnih raziskav TIMSS. Zagotovljena je bila anonimnost sodelovanja $\mathrm{v}$ raziskavi ter neomejen čas. Večina udeležencev je lestvico izpolnila v 5 minutah.

\section{Rezultati}

Pri preverjanju razlik v oblikah agresivnosti med spoloma in med različno starimi udeleženci smo uporabili dvosmerno analizo variance (ANOVA) za neponovljene meritve. $\mathrm{V}$ rezultatih so prikazani učinki spola in starosti na merjene oblike agresivnosti. Učinki interakcije spola in starosti so za posamezne oblike agresivnosti prikazani v Tabeli 1 in Sliki 1.

Ugotovili smo pomemben učinek spola, starosti in interakcije spola in starosti na vse merjene oblike agresivnosti. Učinek interakcije pomeni, da je imela starost drugačen učinek na agresivnost pri moškem v primerjavi z ženskim spolom ter da je imel spol različen učinek na agresivnost glede na opazovano starostno skupino.

$\mathrm{Z}$ analizo variance smo ugovotivili ( pri izvedbi post-hoc testov smo uporabili Bonferronijev popravek za več primerjav), da so razlike med različno starimi skupinami udeležencev statistično pomembne v vseh merjenih oblikah agresivnosti. Učenci, mlajši in starejši, so izražali višje stopnje besedne in telesne agresivnosti $\mathrm{V}$ primerjavi $\mathrm{z}$ dijaki (sliki 1 in 2). Starejši učenci so imeli v primerjavi z mlajšimi učenci in dijaki najvišje ravni agresivnosti do avtoritete (slika 4). Dijaki so imeli pomembno višje stopnje notranje agresivnosti kot obe skupini učencev (slika 3). Znotraj skupine učencev pa so starejši učenci izražali višje stopnje vseh merjenih oblik agresivnosti, telesne, besedne, notranje in agresivnosti do avtoritete, v primerjavi z mlajšimi učenci. V Tabeli 1 vidimo, da je imela starost na agresivnost majhen do zmeren učinek (Cohen, 1988). Največji učinek ima starost na telesno agresivnost, pri kateri smo lahko z razlikami med različno starimi udeleženci pojasnili 11 $\%$ variance. 

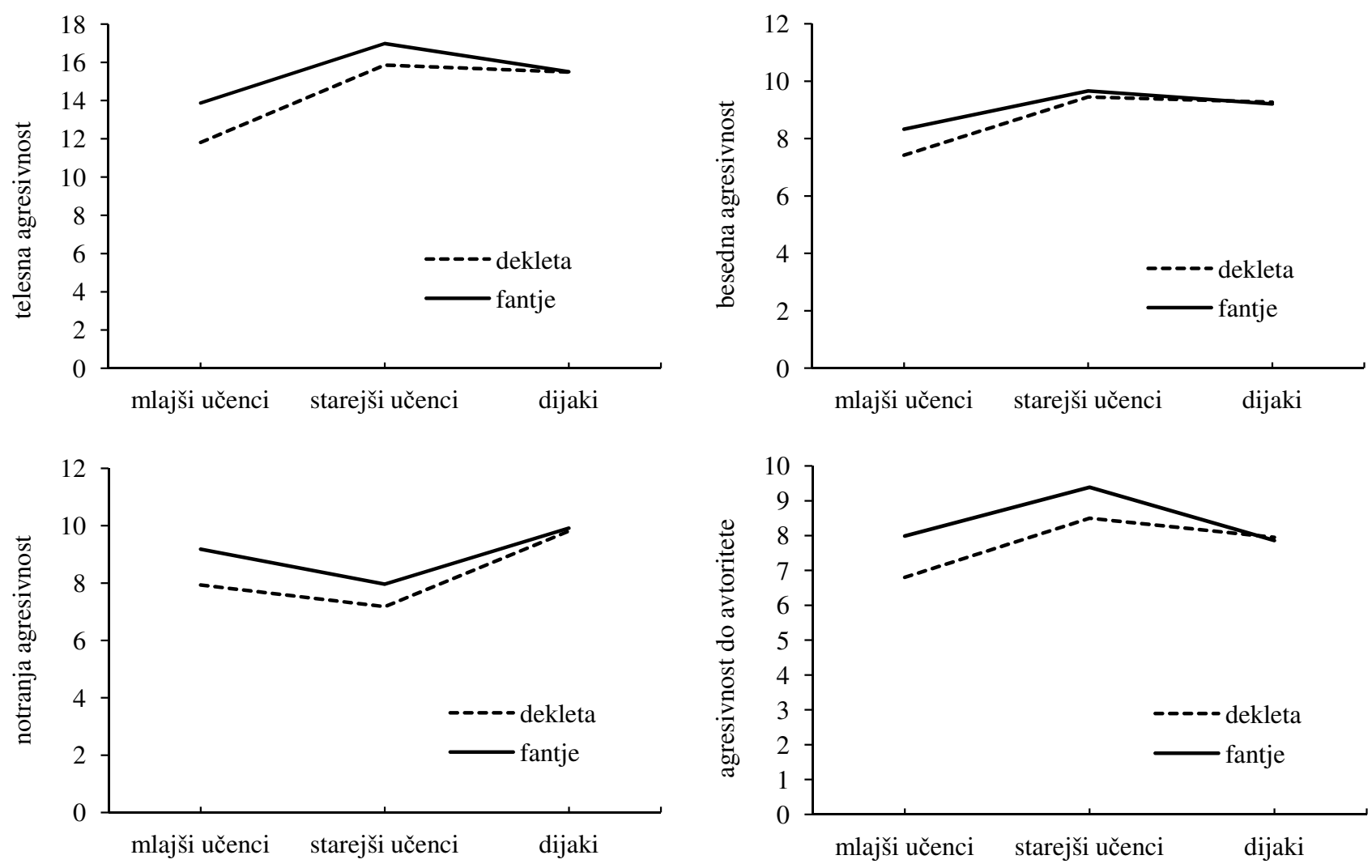

Slika 1. Učinki interakcije spola in starosti na merjene oblike agresivnosti.

Primerjava posameznih oblik agresivnosti med spoloma je pokazala, da so učenci, mlajši in starejši, pokazali višje stopnje telesne in notranje agresivnosti ter agresivnosti $\mathrm{v}$ odnosu do avtoritete $\mathrm{v}$ primerjavi $\mathrm{z}$ učenkami. Mlajši učenci pa so še pokazali pomembno višje ravni besedne agresivnosti v primerjavi z mlajšimi učenkami. Učinek interakcije je pokazal, da so razlike večje med mlajšimi učenci in učenkami kot pa med starejšimi učenci in učenkami. Pri dijakih razlike med dijakinjami in dijaki niso bile statistično pomembne. V Tabeli 1 vidimo, da je spol pojasnil največ $1,2 \%$ variance $\mathrm{v}$ agresivnosti, iz česar smo sklepali na majhno praktično vrednost učinka spola na agresivnost. V skladu s Cohenovimi smernicami za interpretacijo velikosti učinka smo lahko učinke spola opredelili kot majhne. Ko smo primerjali učinke spola in starosti na oblike agresivnosti z odstotki pojasnjene variance, smo ugotovili, da lahko več variance pojasnimo z učinkom starosti v primerjavi z učinkom spola.

\section{Razprava}

Namen raziskave je bil ugotoviti, kako se pri slovenskih učencih in dijakih kažejo razlike $\mathrm{v}$ agresivnosti med spoloma in po starosti. Ker strokovna literatura poroča o razlikah med spoloma $\mathrm{v}$ smeri večje agresivnosti moškega spola, smo to povezavo predpostavili tudi mi. Pri tem nas je zanimalo, kako se te razlike kažejo $\mathrm{v}$ različnih starostnih skupinah ter kako se te različne starostne skupine razlikujejo med seboj v ravni agresivnosti. Raziskava predstavlja celostno analizo, to je analizo razlik po spolu in starosti po posameznih oblikah agresivnosti in je omogočila osnovo za upoštevanje teh razlik v obravnavi agresivnega vedenja $v$ šolah. Ugotovili smo statistično pomemben, a majhen učinek spola na agresivnost in statistično pomemben, zmerno velik učinek starosti na agresivnost. Prav tako smo ugotovili statistično pomembne majhne učinke interakcije spola in starosti na agresivnost.

Posebej smo analizirali razlike po spolu in po starosti za vsako od oblik agresivnosti. Pri vseh oblikah agresivnosti (telesna, besedna, notranja in agresivnost do avtoritete) so se pokazale razlike med spoloma pri mlajših učencih in starejših učencih, ne pa tudi pri dijakih. Pri vseh oblikah agresivnosti so bile razlike med spoloma nekoliko bolj očitne pri mlajših učencih $\mathrm{v}$ primerjavi z starejšimi. Razlike $\mathrm{v}$ agresivnosti so bile torej večje med mlajšimi učenci in učenkami kot pa med starejšimi učenci in učenkami. Učenci so pokazali višje stopnje merjenih oblik agresivnosti kot učenke. Rezultati so skladni z rezultati drugih raziskav na podobnih vzorcih, ki kažejo na pomembne razlike v merjeni agresivnosti med spoloma (Condon idr., 2006; Connor, 2002; Delfos, 2004; Huesmann, 1994; Renfrew, 1997) in tudi z raziskavami na vzorcih 
Tabela 1. Povzetek dvosmerne ANOVE za preverjanje učinkov spola in starosti na različne oblike agresivnosti

\begin{tabular}{llrrrrr}
\hline & Vir & $S S$ & $M S$ & $d f$ & $F^{\sharp}$ & parcialna $\eta^{2}$ \\
\hline Telesna agresivnost & starost & 38939,07 & 19469,54 & 2 & 872,07 & 0,11 \\
& spol & 3464,57 & 3464,57 & 1 & 155,18 & 0,01 \\
& spol x starost & 1532,46 & 766,23 & 2 & 34,32 & 0,00 \\
& napaka & 315595,74 & 22,33 & 14136 & & \\
Besedna agresivnost & starost & 8791,13 & 4395,56 & 2 & 510,26 & 0,07 \\
& spol & 422,69 & 422,69 & 1 & 49,07 & 0,00 \\
& spol x starost & 437,90 & 218,95 & 2 & 25,42 & 0,00 \\
Notranja agresivnost & napaka & 121773,68 & 8,61 & 14136 & & \\
& starost & 8736,56 & 4368,28 & 2 & 529,50 & 0,07 \\
& spol & 1483,78 & 1483,78 & 1 & 179,86 & 0,01 \\
& spol x starost & 517,17 & 258,58 & 2 & 31,34 & 0,00 \\
& napaka & 116618,57 & 8,25 & 14136 & & 0,06 \\
Agresivnost do avtoritete & starost & 7236,13 & 3618,07 & 2 & 409,56 & 1 \\
& spol & 1294,85 & 1294,85 & 1 & 146,58 & 0,01 \\
& spol x starost & 577,41 & 288,70 & 2 & 32,68 & 0,00 \\
& napaka & 124876,26 & 8,83 & 14136 & & \\
\hline
\end{tabular}

\#Vsa $F$ razmerja so statistično pomembna na ravni $p<0,001$.

učencev v Sloveniji (Muršič idr., 2010). Z odkritji teh raziskav je skladna tudi smer razlik, to je, da so dečki pokazali višje stopnje agresivnosti v primerjavi z deklicami (Archer, 1991; Campbell in Henry, 1999; Condon idr., 2006). Buss in Perry (1992) sta pri analizah svoje lestvice ugotovila podobne razlike, in sicer pomembne razlike med spoloma $\mathrm{v}$ telesni in besedni agresivnosti ter sovražnosti, ne pa v dimenziji jeza. Jeza služi kot osnova agresivnemu vedenju tako pri deklicah kot pri dečkih ali, povedano drugače, dečki in deklice doživljajo jezo v enaki meri, čeprav jo dečki izražajo na način, ki je bolj prepoznan v merah samoocenjevanja. Deklice izražanje jeze bodisi zavrejo ali pa izražajo na druge načine, na primer posredno. Razlike med spoloma so lahko posledica različnih načinov njihove socializacije. Deklice naj bi bile s strani staršev, učiteljev in vrstnikov spodbujane, da svoje težave razrešujejo s pomočjo ponotranjenja in ne pozunanjenja (Connor, 2002).

Glede na to, da uporabljena lestvica meri reaktivno agresivnost, katere osnova je jeza, so naši rezultati skladni s teorijo reaktivne in proaktivne agresivnosti. Raziskave (Brendgen idr., 2006) namreč kažejo na pomembne razlike med spoloma $\mathrm{v}$ reaktivni agresivnosti. Samoocenjevalne lestvice, torej tudi uporabljena lestvica, merijo večinoma neposredno agresivnost. Neposredna agresivnost je značilnejša za moški spol in tako lahko smer razlik pripišemu sami metodi merjenja. Glede na razvojne teorije agresivnosti neposredne oblike agresivnosti v mladostništvu niso več tako pogoste (Marjanovič Umek in Zupančič, 2004), kar bi lahko pojasnilo odsotnost pomembnih razlik med dijakinjami in dijaki. Možno je, da bi bile razlike med spoloma pomembne, $\mathrm{v}$ kolikor bi merili posredno agresivnost, ki je za to obdobje bolj značilna. Razvojni psihologi predpostavljajo celo različne poti agresivnosti za oba spola: nekje do starosti pet let razlik med spoloma ni, kasneje $\mathrm{v}$ osnovni šoli $\mathrm{v}$ agresivnosti prednjačijo dečki, v mladostništvu in odrasli dobi pa razlike med spoloma izginejo (Archer in Coyne, 2005; Marjanovič Umek in Zupančič, 2004). Podobno je ugotovil tudi Connor (2002), da so razlike med spoloma večje v otroštvu in do odraslosti izzvenijo. Na upad razlik med spoloma s starostjo so pokazali tudi rezultati učencev, saj so razlike med spoloma večje med mlajšimi učenci in učenkami kot pa med starejšimi učenci in učenkami. Iz vsega naštetega se je pokazala potreba po prenosu in vzporedni uporabi merskih pripomočkov, ki bi merili agresivna vedenja, značilnejša za ženski spol in mladostnike, to je posredne oblike agresivnega vedenja tudi v Sloveniji. V tem trenutku za uporabo v šoli mere posredne agresivnosti še niso na voljo.

Ugotavljali smo tudi učinek starosti na agresivnost in ugotovili nekoliko večji učinek $\mathrm{v}$ primerjavi $\mathrm{z}$ učinkom spola. Primerjali smo izraženost posameznih merjenih oblik agresivnosti pri mlajših učencih, starejših učencih in dijakih. Ugotovili smo podobno kot sta ugotovili K. M. J. Lagerspetz in K. Björkqvist (citirano v: Huesmann, 1994), ki sta primerjali različne oblike agresivnost 8-, 11- in 15-letnikov. Ugotovili sta, da so najbolj neporedno agresivni 11-letniki . V naši raziskavi so dijaki izkazali v primerjavi z učenci najvišje stopnje notranje agresivnosti, medtem ko so pri agresivnosti do avtoritete bili med obema skupinama učencev. Agresivnost do avtoritete je bila najvišja pri starejših učencih in najnižja pri mlajših učencih.

Ko smo primerjali rezultate učencev (kot predstavnike obdobja srednjega otroštva in zgodnjega 
mladostništva) in dijake (kot predstavnike obdobja poznega mladostništva) so bili ti skladni $\mathrm{z}$ rezultati longitudinalnih raziskav, ki kažejo upad agresivnega vedenja od otroštva do mladostništva (Cairns idr., 1989), še posebej pri telesni agresivnosti (Cairns idr., 1989; Nagin in Tremblay, 2001; Romano idr., 2005; Tremblay 2000). Dijaki so namreč kazali nižje stopnje agresivnosti kot učenci, tako mlajši kot starejši. Znotraj skupine učencev nismo opazili tega trenda, tu so namreč starejši učenci izkazali višje stopnje agresivnosti od mlajših učencev. Naša raziskava je primerjala agresivnost učencev v 4. in 8. razredu osnovne šole. Raziskave (Campano in Munakata, 2004), ki so zajele mlajše učence, to je učence v 2. razredu in jih spremljale do 4. razreda, so ob obeh merjenjih agresivnosti ugotovile višje stopnje agresivnosti učencev v 4. razredu. Iz tega lahko sklepamo, da sicer agresivnost v otroštvu narašča, vendar nato upade do obdobja zgodnjega mladostništva. Raziskave, ki smo jih navajali do sedaj, govorijo o splošni agresivnosti ali bolj specifično o telesni agresivnosti. Druge, ki se osredotočajo na besedno in notranjo agresivnost, pa poročajo o porastu te vrste agresivnosti od obdobja otroštva do mladostništva (Romano idr., 2005). To bi lahko pojasnilo razliko med mlajšimi in starejšimi učenci v našem primeru, saj ti učenci prehajajo od otroštva do mladostništva, medtem ko lahko dijake umestimo v pozno mladostništvo ali na začetek prehoda $\mathrm{v}$ zgodnjo odraslo dobo. S tem se ujema tudi podatek, da so dijaki kazali višje ravni notranje agresivnosti od učencev. Glede na ta podatek, lahko posredno sklepamo na možnost razvojnega trenda od zunanjih oblik agresivnosti k notranjim. Te ugotovitve bi potrdile stabilnost agresivnosti in torej drugačno izražanje agresivnosti $\mathrm{v}$ obdobju poznega mladostništva in zgodnje odrasle dobe in s tem poudarile praktično vrednost spremljanja notranje agresivnosti in njenih posledic, kot je na primer samopoškodovalno vedenje. Te razvojne povezave bi bilo potrebno potrditi z dodatnimi raziskavami, ki bi vključevale vzdolžen raziskovalni načrt. Moramo namreč poudariti, da naši podatki niso omogočali longitudinalnih primerjav in so tako lahko dobljene razlike lahko bile tudi posledica raznovrstnih razlik med kohortama mlajših in starejših učencev ter dijakov in ne nujno zgolj posledica razlik v starosti.

Raziskava je podala pomembne ugotovitve o razlikah med spoloma in med različnimi starostnimi skupinami slovenskih učencev in dijakov v agresivnosti. $\mathrm{V}$ analize so bili vključeni trije veliki reprezentativni vzorci, kar veča posplošljivost rezultatov. Ker je prispevek vključeval analizo učinkov spola in starosti ter njune interakcije na različne oblike agresivnosti, lahko govorimo o bolj celostni analizi agresivnosti. Z analizo razlik po posameznih oblikah imajo rezultati praktično vrednost predvsem za obravnavo agresivnosti v šolah. Višje stopnje notranje agresivnosti dijakov nas tudi nadalje usmerjajo na obravnavo tovrstnih oblik agresivnosti v srednjih šolah. Dodatno bi bilo smiselno glede na dobljene rezultate preveriti vzorec razlik pri posredni agresivnosti in na ta način tematiko še bolj celostno zajeti.

Pri interpretaciji rezultatov pa se moramo zavedati tudi nekaterih omejitev raziskave. Te se v prvi vrsti nanašajo na omejenost reprezentativnosti vzorca dijakov (t.j. vzorec dijakov je reprezentativen za dijake zadnjih letnikov programov splošne mature in ne za vse dijake vseh srednješolskih programov) in odsotnost longitudinalnega raziskovalnega načrta za oceno razvojnih trendov. $\mathrm{V}$ nadaljnjem raziskovanju bi bilo $\mathrm{v}$ analize smiselno vključiti še druge starostne skupine.

\section{Literatura}

Archer, J. (1991). The influence of testosterone on human aggression. British Journal of Psychology, 82, 1-28.

Archer, J. in Coyne, S. M. (2005). An integrated review of indirect, relational, and social aggression. Personality and Social Psychology Review, 9(3), 212-230.

Brendgen, M., Vitaro, F., Boivin, M., Dionne, G. in Perusse, D. (2006). Examining genetic and environmental effects on reactive versus proactive aggression. Developmental Psychology, 42(6), 1299-1312.

Buss, A. H. in Perry, M. (1992). The Aggression Questionnaire. Journal of Personality and Social Psychology, 63(3), 452-459.

Cairns, R. B., Cairns, B. D., Neckerman, H. J., Ferguson, L. L. in Gariepy, J. L. (1989). Growth and aggression: 1. Childhood to early adolescence. Developmental Psychology, 25(2), 320-330.

Campano, J. P. in Munakata, T. (2004). Anger and aggression among Filipino students. Adolescence, 39(156), 757-763.

Campbell, C. R. in Henry, J. W. (1999). Gender differences in self-attributions: Relationship of gender to attributional consistency, style, and expectations for performance in a college course. Sex Roles, 42(1/2), 95-104.

Carr, A. (1998). The handbook of child and adolescent clinical psychology. London: Routledge.

Cohen, J. (1988). Statistical power analysis for the behavioral sciences. Hillsdale, NJ, USA: Lawrence Erlbaum Associates.

Condon, L., Morales-Vives, F., Ferrando, P. J. in VigilColet, A. (2006). Sex differences in the full and reduced versions of the aggression questionnaire: A question of differential item functioning? European Journal of Psychological Assessment, 22(2), 92-97.

Connor, D. F. (2002). Aggression and antisocial behaviour in children and adolescents: Reserach and treatment. New York, USA: Guilford press.

Connor, D. F., Steingard, R. J., Cunningham, J., Andreson, J. J. in Melloni, R. (2004). Proactive and reactive ag- 
gression in referred children and adolescents. American Journal of Orthopsychiatry,74(2), 136-139.

Crick, N. R., Ostrov, J. M. in Werner, N. E. (2006). A longitudinal study of relational aggression, physical aggression, and children's social-psychological adjustment. Journal of Abnormal Child Psychology, 34(2), 127-138.

Delfos, M. F. (2004). Children and behavioural problems - anxiety, aggression, depression and ADHD - a bio psychological model with guidelines for diagnostics and treatment. London: Jessica Kingsley Publishers.

Ferris, C. F. (1996). Understanding aggressive behaviour in children. New York, USA: The NewYork Academy of Science.

Finn, K. V. in Frone, M. R. (2003). Predictors of aggression at school: The effect of alcohol-related alcohol use. NASSP Bulletin, 87(363), 38-54.

Fite, P. J., Raine, A., Stouthamer-Loeber, M., Loeber, R. in Pardini, D. A. (2010). Reactive and proactive aggression in adolescent males: Examining differential outcomes 10 years later in early adulthood. Criminal Justice and Behaviour, 37(2), 141-157.

Flannery, D. J., Vazsonyi A. T. in Waldman, I. D. (2007). The Cambridge handbook of violent behaviour and aggression. Cambridge, England: Cambridge University Press.

Fossati, A., Maffei, C., Acquarini, E. in DiCeglie, A. (2003). Multi group confirmatory component and factor analyses of the Italian version of The Aggression Questionnaire. European Journal of Psychological Assessment, 19(1), 54-65.

Hubbert, J. A., McAuliffe, M. D., Morrow, M. T. in Romano, L. J. (2010). Reactive and proactive aggression in childhood and adolescence: Precursors, outcomes, processes, experiences, and measurement. Journal of Personality, 78(1), 95-118.

Hudley, C. (1993). Comparing teacher and peer perception of aggression: An ecological approach. Journal of Educational Psychology, 82(2), 377-384.

Huesmann, L. R. (1994). Aggressive behaviour - current perspectives. New York \& London: Plenum press.

Huesmann, L. R., Eron, L. D., Lefkowitz, M. M. in Walder, L. O. (1984). Stability of aggression over time and generations. Developmental Psychology, 20, $1120-1134$.

Japelj Pavešić, B., Svetlik, K., Kozina, A. in Rožman, M. (2009). Znanje matematike in fizike med maturanti v Sloveniji in po svetu [Matura Students' Math and Physics Achievement in Slovenia and Abroad]. Ljubljana, SLO: Pedagoški inštitut.

Japelj Pavešić, B., Svetlik, K., Kozina, A. in Rožman, M. (2008). Matematični dosežki Slovenije v raziskavi TIMSS 2007 [Slovene Math Schievement in TIMSS 2007]. Ljubljana, SLO: Pedagoški inštitut.

Kocmur, M. (1999). Nevrotske stresne in somatoformne motnje [Neurotic, Stress and Somatic Disturbances]. V M.Tomori in S. Ziherl (ur.), Psihiatrija [Psychiatry](str. 229-258). Ljubljana, SLO: Medicinska fakulteta.
Kozina, A. (2012, v recenziji). The LA Aggression Scale for elementary and secondary school students: Examination of psychometric properties of a new multidimensional measure of self reported aggression. Journal of Psychoeducational Assessment.

Krall, H. (2003). Mladina in nasilje: teoretične koncepcije in perspektive pedagoškega ravnanja [Youth and Violence: Teoretical Concepts and Educatuonbal Perspectives]. Sodobna pedagogika, 54(2), 10-25.

Krug, E. G., Dahlberg, L. L., Mercy, J. A., Zwi, A. B. in Lozano, R. (ur.). (2002). World report on violence and health. Geneva: World Health Organization.

Lamovec, T. (1988). Priročnik za psihologijo motivacije in emocij [Manual for the psychology of motiavtion and emotions]. Ljubljana, SLO: Filozofska fakulteta, Oddelek za psihologijo.

Lagerspetz, M. J., Bjorqvist, K. in Peltonen, T. (1988). Is indirect aggression typical for females? Gender differences in aggressiveness in 11- to 12-years old children. Aggressive Behaviour, 14, 403-414.

Loeber, R. in Hay, D. (1997). Key issues in the development of aggression and violence from childhood to early adulthood. Annual Review of Psychology, 48, 371-410.

Marjanovič Umek, L. in Zupančič, M. (2004). Razvojna psihologija [Developmental Psychology]. Ljubljana, SLO: Znanstvenoraziskovalni inštitut Filozofske fakultete.

Muršič, M., Milivojević, Z., Brvar, B., Filipčič, K., Lešnik Muganioni, D. in Pušnik, M. (2010). Znanje o čustvih za manj nasilja $v$ šoli [Emotion Regulation for Less Violence in Schools]. Ljubljana, SLO: Inštitut za kriminologijo.

Nagin, D. S. in Tremblay, R. E. (2001). Parental and early childhood predictors of persistent childhood aggression in boys from kindergarten to high school. Archives of General Psychiatry, 58, 389-394.

Olweus, D. (1979). Stability of aggression patterns in males: A review. Psychological Bulletin, 86, 852-875.

Overton, W. F. (2004). Trajectories of physical aggression from toddlerhood to middle childhood. Oxford, UK: Blackwell Publishing.

Poulin, F. in Boivin M. (2000). Reactive and proactive aggression: Evidence of a two-factor model. Psychological Assessment, 12(2), 115-122.

Renfrew, J. W. (1997). Aggression and its causes - a bio psychological approach. New York, USA: Oxford University Press.

Romano, E., Tremblay, R. E., Boulerice, B. in Swisher R. (2005). Multilevel correlates of childhood physical aggression and pro social behaviour. Journal of $A b$ normal Child Psychology, 33(5), 565-578.

Tremblay, R. E. (2000). The development of aggressive behaviour during childhood: What have we learned in the past century? International Journal of Behavioural Development, 24(2), 129-141.

Van Lier, P. A. C. in Crijhen, A. A. M. (2005). Trajectories of peer nominated aggression: risk status, predictors 
and outcomes. Journal of Abnormal Child Psychology, 33(1), 99-112.

Vitaro, F., Brendgen, M. in Barker, E. D. (2006). Subtypes of aggressive behaviours: A developmental perspective. International Journal of Behavioural Development, 30(1), 12-19.

Wilkowski, B. M. in Robinson, M. D. (2010). The anatomy of anger: An integrative cognitive model of trait anger and reactive aggression. Journal of Personality, 78(1), 9-38. 